\section{Entrevista: Nelson Rodrigues dos Santos}

Interview: Nelson Rodrigues dos Santos
Resumo Nelson Rodrigues dos Santos fez um longo depoimento, em dezembro de 2005, para o Observatório de Técnicos em Saúde da Escola Politécnica de Saúde Joaquim Venâncio/Fiocruz. O objetivo era fazer o registro da trajetória de um líder histórico tanto da luta pela democracia quanto da reforma sanitária em um projeto desenvolvido pelo Observatório sobre memória da educação profissional em saúde no Brasil, centrado nas décadas de 1980 e 1990, as quais testemunharam momentos de grande tensão política no país, representados pela redemocratização, reforma sanitária, Assembléia Nacional Constituinte e guinada neoliberal nas políticas de saúde. Nesta entrevistal, uma síntese revista e atualizada daquele depoimento, Nelsão, como é chamado pelos amigos, fala sobre a sua formação e a opção pela Saúde Coletiva, discute temas relacionados ao setor saúde brasileiro nas últimas décadas, abordando desde a gênese do SUS até as vitórias e derrotas das políticas públicas na área social. Graduado em medicina e com doutorado em medicina preventiva pela Universidade de São Paulo, respectivamente em 1961 e 1967, foi professor titular de Saúde Coletiva na Universidade Estadual de Londrina e Consultor da Opas/OMS. Atualmente, Nelsão é professor colaborador da Universidade Estadual de Campinas e presidente do Instituto de Direito Sanitário Aplicado (Idisa).
Abstract Nelson Rodrigues dos Santos made a long testimonial, in December 2005, to the Health Technician Observatory of the Joaquim Venâncio Polytechnic School of Health (Fiocruz). The goal was to record the trajectory of a historical leader, both in the fight for democracy and in the sanitary reform in a project developed by the Observatory about the memory of professional education for health in Brazil. It focused on the 1980's and 1990's, which witnessed moments of great political tension in the country, as represented by re-democratization, sanitary reform, the National Constituent Assembly, and the neoliberal turn in the health policies. In this interview, a revised and updated synthesis of that testimonial, "Nelsão," as he is called by his friends, talks about his background and about the choice he made for Collective Health, discusses themes related to the Brazilian health sector in the past few decades, ranging from the genesis of the SUS to the victories and defeats of the public policies in the social area. A graduate in medicine and holding a doctoral in preventive medicine from the University of São Paulo, respectively in 1961 and 1967, he was a full professor of Collective Health at the Federal University of Londrina and a Consultant for Opas/OMS. Nelsão is currently a collaborating professor at the State University of Campinas and the president of the Applied Sanitary Law Institute (Instituto de Direito Sanitário Aplicado, Idisa). 


\section{Revista}

Como foi sua entrada na saúde pública?

\section{Nelson Rodrigues dos Santos}

Nos meus últimos anos de medicina, eu morava dentro de um hospital psiquiátrico, dava plantão. Paralelamente, tinha uma militância em entidades estudantis: Centro Acadêmico Oswaldo Cruz da minha escola, União Estadual dos Estudantes e União Nacional dos Estudantes. Minha formação foi muito marcada na universidade por militância política. Peguei a geração universitária que mais militou politicamente, com mais visão de futuro, de utopias... Aquele desenvolvimentismo do Juscelino, o PIB crescendo muito, tinha pleno emprego, não existia a figura do desemprego. O mundo era bipolarizado na época, entre Estados Unidos e União Soviética, e nessa bipolarização o Brasil surgia como liderança ao lado do Egito e Índia, e saíam pelo meio da Guerra Fria com a estratégia desenvolvimentista - e muito inclinado a Estado de bem-estar social, na linha que podemos rotular de centro-esquerda, que era o que vivíamos no Brasil. Numa conjuntura internacional e nacional dessas, as entidades estudantis se punham com tudo nessa militância, e eu fiz parte dessa geração. Apesar de gostar de psiquiatria, aceitei convite de um dos ícones da pesquisa em saúde pública brasileira, Samuel Pessoa, já aposentado, que acompanhava minha militância política como estudante e minhas potencialidades profissionais. Ele estava organizando, no Instituto de Medicina Tropical na USP, uma área de geografia médica com estudos muito novos relacionados à ecologia, os nichos ecológicos, os ecossistemas, as doenças transmissíveis e os determinantes sociais das doenças, e me convidou para ser assistente dele no meu primeiro ano de formado. Essa opção foi muito clara, muito rápida e inequívoca, porque ia ao encontro da minha linha de militância política nos movimentos estudantis, de um projeto de desenvolvimento nacional e de uma visão socialista da sociedade. Aí eu deixei com a psiquiatria até em nível ideológico. Trabalhava no hospital privado mais badalado na época, que tinha os psiquiatras mais competentes e respeitados da linha da Sociedade Brasileira de Psicanálise, e estes me apontavam que eu jamais poderia ser um psicanalista em setor público, que eu só podia ser bem-sucedido se optasse pela clínica particular. Quando comecei a ver que aquilo era verdade, a psicanálise naquela época só podia se desenvolver no mercado, com clientela particular, eu fiz a opção. Foi açúcar no mel: de um lado, esse desafio ideológico; de outro, o Samuel Pessoa me convidando. Então, a minha entrada na saúde pública foi essa.

\section{Revista}

Era vinculado a algum partido?

\section{Nelson Rodrigues dos Santos}

Eu era do antigo Partido Comunista Brasileiro, o PCB. Isso quando estudante, até um ou dois anos de formado - até 1964. Eu era de uma parte do PCB que, apesar de todo o peso do golpe militar de direita explícito no nosso país, ainda jogava na acumulação de forças, nas alianças amplas, enquanto parte foi para as diversas frações de luta armada. Não só parte do $\mathrm{PCB}$, mas muitas organizações de esquerda revolucionária começaram a surgir para contrapor ao golpe uma ação mais clandestina e mais violenta. Na minha militância, eu tinha incorporado muito a visão de conquistar corações e mentes para as causas, inclusive na ditadura. Nos primeiros anos da ditadura, eu me afastei do partido, porque continuar partidarizado significava entrar numa clandestinidade e num risco de pôr em xeque o tipo de militância que eu queria continuar praticando. Esse exercício político marcou muito meu desenvolvimento profissional, minhas opções profissionais.

\section{Revista}

E a vinculação com o Centro Brasileiro de Estudos de Saúde (Cebes), quando se deu?

\section{Nelson Rodrigues dos Santos}

Foi posterior. Fui da geração dos sanitaristas que viveram a ditadura toda e me dediquei profundamente à pesquisa epidemiológica. Fiz doutorado na USP em esquistossomose no Vale do Paraíba, onde trabalhei alguns anos a questão da mobilização da população rural para compartilhar com os poderes municipal e estadual as medidas de saneamento. Em 1970, fui convidado para a Universidade Estadual de Londrina. Fiz parte do time que iniciou a faculdade de medicina, entre clínicos, cirurgiões, pediatras etc. Organizei a primeira equipe de saúde pública, levando companheiros e 
companheiras de São Paulo. Meu deslanche na saúde pública, de uma maneira sistemática e politicamente consciente, foi em Londrina. Ali eu era coordenador de um departamento que se chamava Saúde Comunitária, com uma equipe multiprofissional. Desde o começo, tivemos cientista social, educador, médico, enfermeiro, e pegamos a maior parte dos anos: primeiro, segundo, terceiro e quarto ano. Fundamos, junto com a prefeitura municipal, os primeiros postos de saúde periféricos da zona urbana. O norte do Paraná tinha uma população rural percentualmente grande, o povoamento e a colonização na onda do café no norte do Paraná desde o começo impediu latifúndios, foi em pequena propriedade, e isso deu uma densidade muito grande na zona rural. Apesar da grande polarização da cidade de Londrina, a zona rural dela tinha o mesmo número de habitantes da zona urbana. Eram vilas, entroncamentos rurais. Nessas vilas rurais, nós começamos também a instalar postos de saúde.

\section{Revista}

É nessa época que começa a organização dos departamentos de medicina preventiva?

\section{Nelson Rodrigues dos Santos}

É nessa época. Quando eu estava em Londrina, o Sérgio Arouca estava em Campinas. O Arouca e sua equipe estavam atuando, pela esquerda, em plena ditadura, em Campinas. Estava nascendo uma visão de saúde pública com coloridos diferentes em vários lugares: Campinas, Montes Claros, Londrina, Niterói, na Ensp no Rio, na Faculdade de Saúde Pública de São Paulo, no Rio Grande do Sul, em Salvador, em Recife. Depois pipocaram muito mais, mas essas cinco ou seis, nos anos 70, cada uma a seu modo, começaram a encarar a saúde pública numa visão mais sistêmica de atenção integral, e não só o preventivismo. O Arouca despontou com a tese dele sobre o dilema preventivista, dando todo o embasamento teórico da decadência do paradigma preventivista na saúde pública. Isso nos ajudou muito - um dos nossos comprovando teoricamente o que a nossa intuição dizia. Minha linha era mais empírica, e nossas unidades de saúde já nasciam na atenção integral, com atenção clínica de adultos, de crianças, de mulheres. E era inequívoco - sabíamos que se fôssemos partir somente para vacinar, para fazer vigilância sanitária e proteção do meio ambiente, íamos ficar isolados da comunidade, ela não ia aderir.

\section{Revista}

O Prev-Saúde (Programa Nacional de Serviços Básicos de Saúde) já estava se desenvolvendo nesta época?

\section{Nelson Rodrigues dos Santos}

Foi um pouco mais à frente, no final dos anos 70. Ele nasce de 1977 para 1978: começa a ser elaborado em 1977, vem à luz em 1978 - quando eu já estava em Brasília. Em Londrina, fui preso pelo DOI-Codi (Destacamento de Operações de Informações - Centro de Operações de Defesa Interna). Havia uma reitoria da universidade que era da direita, extremamente prepotente e carreirista como o reitor. Nessa época da ditadura, todos os órgãos públicos tinham uma famigerada assessoria de segurança e informação ligada ao sistema central da ditadura. O Ministério da Saúde (MS) também, bem como as secretarias estaduais. Vocês não são da época da ditadura, ela não era só o ditador lá em cima, não, tinha toda a escadinha hierárquica. Todas as perseguições, invejas e competitividades neuróticas se dão em todos os escalões de toda a hierarquia; você sente a ferocidade da ditadura porque o seu colega, o seu dirigente imediato, pode te entregar ou falsificar provas contra você.

\section{Revista}

Mas essa prisão tem a ver com a militância dentro da universidade? Com a discussão da política de saúde? Ou com a história anterior como quadro do $\mathrm{PCB}$ ?

\section{Nelson Rodrigues dos Santos}

As duas coisas. Meu nome estava rolando como ex-militante do PCB, mas para uma ditadura todos são suspeitos até que se prove o contrário. Em 1973, há quase dez anos já não tinha militância no PCB, mas dentro da ditadura haviam listas de endereços apreendidas, e meu nome constava em algumas delas. Eu já tinha ficha no Dops (Departamento de Ordem Política e Social) em São Paulo. Como se isso não bastasse, na Universidade de Londrina a assessoria de segurança e informação da universidade fez contato com o Dops em São Paulo, e aí foi fácil. Eu fui 
preso pelo DOI-Codi. Libertado um mês após, reassumi meu cargo. Eu era diretor do Centro de Ciências da Saúde, mas o reitor, pelos mecanismos administrativos da universidade, impediu qualquer possibilidade de espaço de atuação, apesar de toda solidariedade dos docentes e alunos. Eu estava no ostracismo total em Londrina quando veio o convite da Opas (Organização Pan-Americana da Saúde) em Brasília. Aí é que fui participar do Programa de Preparação Estratégica de Pessoal de Saúde (PPREPS/Opas) e, de quebra, no Prev-Saúde. Aceitei esse convite para ir para a Opas em Brasília em 1977.

\section{Revista}

O senhor fez parte daquela equipe que estava discutindo o PPREPS?

\section{Nelson Rodrigues dos Santos}

Fiz. Fui coordenado pelo Carlyle Guerra de Macedo durante um ano e meio. Faziam parte desse grupo César Vieira, que hoje está em Washington, Izabel dos Santos, que vocês conhecem, Alberto Pellegrini, de Campinas, Salazar, do Chile, Danilo Garcia, de São Paulo, e eu. O PPREPS teve um papel muito importante na questão, era um programa estratégico de desenvolvimento de recursos humanos, um convênio da Opas com o Ministério da Saúde, e atuava diretamente nas secretarias estaduais de saúde. Em 1977, não havia ainda nem Cosems (Conselho de Secretarias Municipais de Saúde), nem Conasems (Conselho Nacional de Secretários Municipais de Saúde), nem secretarias municipais de saúde de maior expressão em nível nacional. Nos anos 70, os prefeitos municipais das cidades médias começaram a se preocupar com saúde, pelo problema da explosão demográfica - as cidades médias quase que dobraram sua população em dez anos; Campinas foi uma, Londrina outra - e a pauperização do interior. A migração rural-urbana foi muito intensa na época e gerou uma tensão social muito grande nas periferias urbanas. No final dos anos 70 e início dos anos 80, o próprio governo federal, em plena ditadura, se preocupou em ter assessoria do Banco Mundial para os primeiros programas compensatórios focalizantes, para segurar as pontas nas periferias urbanas. $\mathrm{O}$ Ministério da Saúde, inclusive, fez um projeto cujo nome era Projeto Periferia Urbana. Os prefeitos começaram a se preocupar em colocar dirigentes na área da saúde municipal capazes de aplacar as tensões sociais da periferia. Isso é um fenômeno intenso no período. Na época, até por intuição, por pragmatismo, começou a ficar muito comum prefeitos comprarem ou contratarem kombis velhas, porem um médico na ombi, e cada dia da semana era um bairro. Esse assistencialismo, que chamavam de 'postos volantes', deu lugar, na seqüência, a um assistencialismo mais fixo. Eram médicos clínicos, que não tinham formação em saúde pública mas escolhidos em conformidade com o prefeito, ou pelo jeitão populista do próprio médico. Os próprios prefeitos pagavam os médicos, inclusive dentistas também muitas vezes, que começaram a ir em kombis nas periferias de cidades médias. E depois começaram a alugar casinhas, um aluguel muito barato, casinhas abandonadas nas periferias urbanas e instalar os primeiros postinhos de saúde. Foi gradativo: os postinhos e casinhas periféricas alugadas sucederam os volantes. Depois foram ficando só os postinhos fixos. E numa terceira etapa, já nos anos 80, ainda antes da VIII Conferência [Nacional de Saúde], as cidades médias começaram a alugar casas melhores ou construir prédios próprios, definitivos, municipais para serem centros de saúde. O movimento municipal de saúde vai se fortalecendo porque não é medido só pela evolução das kombis, das casinhas alugadas e depois dos postinhos construídos. Ele é medido pela entrada dos sanitaristas. O Cebes é fundado no final dos anos 70, e não é à toa. Ele é fundado nessa época porque as secretarias estaduais de saúde estavam com poucos quadros para dar conta da pressão dos prefeitos. Diante dessa tensão nas periferias urbanas, no caso do estado de São Paulo, a Faculdade de Saúde Pública da USP e, no Rio de Janeiro, a Ensp, quase simultaneamente, tiveram reações muito sábias: um secretário de saúde famoso de São Paulo, Walter Leser, brigou com a Faculdade de Saúde Pública de São Paulo e financiou, com recursos da secretaria de saúde, os famosos cursos curtos, de um semestre. Essas turmas dos cursos curtos, mais politizadas à esquerda, no final dos anos 70 , criaram o Cebes. E a maior parte começou a ir para a prefeitura, e não para o estado. O estado não tinha como abrir centros de saúde, mas oferecia esses sanitaristas - primeiro contratou os sanitaristas oferecendo para as prefeituras utilizá- 
los na rede de postinhos, depois as prefeituras começaram a contratar esses sanitaristas dos cursos curtos. E a Ensp não fez curso curto, mas fez os 'cursos regionalizados' - a distância, em Florianópolis, Porto Alegre, Salvador, Recife, várias capitais. Quando vim para Campinas, em 1978, começamos a fazer cursos de saúde pública no departamento de medicina preventiva da Unicamp, e me balizei muito na evolução dos programas dos cursos curtos de São Paulo e nos cursos regionalizados da Ensp. Juntando essas duas coisas, montamos aqui em Campinas nosso curso de saúde pública, que evoluiu, desenvolveu-se e desdobrou-se a partir dos anos 90 em vários cursos de especialização, aprimoramento, residência e pós-graduação.

\section{Revista}

E como foi o trabalho do PPREPS? Tinha financiamento do Banco Mundial?

\section{Nelson Rodrigues dos Santos}

Não. Eu diria que foi um trabalho antecipatório. O Carlyle Guerra Macedo era um sanitarista reconhecido internacionalmente, um grande analista político, acompanhava as tendências mundiais - a gente já discutia naquela época o que é um programa compensatório e o que é um programa estruturante, de nível permanente, de direitos de saúde. Mais tarde, houve um histórico Simpósio sobre a construção de um sistema de saúde, em 1979, na Câmara Federal em Brasília, num momento muito estratégico, conscientemente planejado, porque dentro do Congresso Nacional já crescia uma massa crítica - ainda minoritária - mas com uma certa consistência, principalmente de deputados, já começando a pensar e atuar para acabar a ditadura. Era a bancada democrática. A partir de 1975 tem início a distensão lenta e gradual, que correspondia também a uma mobilização da sociedade - foi uma pró-atividade. A sociedade não foi objeto de uma estratégia de cima para baixo, da democratização lenta e gradual. A sociedade foi muito ativa, fazendo pressões cada vez maiores, abandonando a linha da guerrilha e entrando para uma linha de grande aglutinação e grande força social, político-social. A sociedade organizada começou a crescer abertamente nos sindicatos, nas associações culturais, na intelectualidade, na classe média, a própria chamada burguesia nacional começou a perder o interesse no projeto econômico da ditadura, e a sociedade começou a avançar. A bandeira das liberdades democráticas era muito mobilizante: era suprapartidária. Evidentemente, o antigo MDB era o partido que mais aglutinava, tinha mais massa de parlamentares na luta pelas liberdades democráticas, e no bojo desse fenômeno a área da saúde construiu esse Simpósio.

\section{Revista}

Quem estava à frente da organização?

\section{Nelson Rodrigues dos Santos}

$\mathrm{Na}$ época foi um deputado que antes era da Arena, depois foi para o MDB: Ubaldo Dantas; o outro era o Max Mauro, do Espírito Santo, também do MDB. Esse Simpósio de 1979 albergou nos corredores e nas salas da Câmara dos Deputados em Brasília por volta de 600 pessoas, que, em nome de discutir saúde, encontraram um espaço democrático além da saúde. Inclusive, um monte de gente clandestina procurada pelo Dops apareceu lá! Foi o primórdio de um fenômeno que veio a se estender pelos anos afora, que era o encontro da sociedade organizada com o Legislativo. Houve a grande crise da Previdência Social. A crise da Previdência foi o governo central passando a mão na grana da Previdência, nas suas reservas, para construir a ponte Rio-Niterói, a Transamazônica, grandes hidrelétricas e outros gastos enormes, além dessas mega-obras. A Previdência entra numa baita crise e arrasta a assistência à saúde. A racionalização do Inamps (Instituto Nacional de Assistência Médica da Previdência Social) não deu conta de encarar a falta de recursos da Previdência. Nessa conjuntura toda aconteceu o Simpósio, que atraiu a vertente do Cebes, a maior força na época - a Abrasco (Associação Brasileira de Pós-Graduação em Saúde Coletiva) tinha acabado de ser fundada também, no final dos anos $70-$, a intelectualidade de pós-graduação em saúde coletiva, outras forças também, sindicais e não sindicais, especialmente a força parlamentar. O relatório desse Simpósio apontava pela primeira vez com clareza a crise na prevenção e na cura - a crise sistêmica -, e apontava para algumas diretrizes capazes de integrar o que estava desintegrado ao nível das instituições. Isso deve ter tido um peso, porque exatamente em 1980, o João Figueiredo, presidente de plantão da ditadura, contava com 
assessores menos truculentos, que não eram da esquerda, não eram desses movimentos do Cebes nem do Simpósio da Câmara, mas tinham um pouco mais de versatilidade. Um deles era o Aloísio Sales, que veio a ser depois presidente do Inamps, e criou o Conasp (Conselho Nacional de Saúde Previdenciária). Carlos Gentile de Mello foi o grande estudioso que denunciava a privatização da saúde previdenciária. Daí nascem as AIS (Ações Integradas de Saúde), por força do movimento municipal, que nessa altura já era um movimento mais consistente. Em 1997, havia ocorrido o Encontro dos Secretários Municipais de João Pessoa, reunindo os secretários do Nordeste, e no ano seguinte o de Campinas e, em 1979, o de Niterói. O movimento municipal teve um peso, ainda que não decisivo, nas AIS. Elas já nasceram numa proposta sistêmica, mas ainda num primeiro degrau, que era integrar o que estava desintegrado. Integrar Inamps e Ministério da Saúde, as coordenações regionais do Inamps nos estados com as secretarias estaduais. Aí ocorre o II Simpósio da Câmara dos Deputados, em 1982. Esse II Simpósio foi convocado pela militância do Cebes e da Abrasco, a militância da reforma sanitária.

\section{Revista}

O PPREPS é antecipatório de quê?

\section{Nelson Rodrigues dos Santos}

Do que seria discutido nesse II Simpósio de 1982 e, depois, na VIII Conferência. O tema recursos humanos se tornou pauta importante da VIII Conferência e foi pauta marcante no II Simpósio. No I Simpósio se pressionou para integrar o que estava desintegrado, a ênfase era a racionalização. O II Simpósio entrou na fase de formulação de estratégias, apontando para um sistema de saúde, que ainda não era o SUS (Sistema Único de Saúde), mas um sistema nacional de saúde. Denunciava a lei de 1975 - a 6229 - que carimbava dois sistemas de saúde: o assistencial e o preventivo, impedindo um sistema nacional. Em 1982, fez-se crítica da lei anterior e se pressionou para uma nova lei da saúde, apontando para uma visão sistêmica. Naquele contexto, as AIS já estavam colocadas, embora não concretizadas, mas já eram uma bandeira, e o II Simpósio fez uma pressão enorme para se começar a sanar os problemas das AIS. Estes problemas começaram a ser sana- dos no final de 1982 e 1983. Em 1983, as AIS deslancharam. Esse II Simpósio de 1982 trouxe a força do Poder Legislativo sinergizado pelo movimento social da reforma sanitária. Esse sinergismo havia começado no Simpósio de 1979 e deu um salto no Simpósio de 1982, apontando o que viria a ser a VIII Conferência, quatro anos depois. Verdade é que 1983, 1984 e 1985 são três anos extremamente férteis e decisivos no movimento crescente que vai dar na VIII Conferência. Mas o Simpósio de 1982 deu um patamar.

\section{Revista}

\section{E o Conasems?}

\section{Nelson Rodrigues dos Santos}

Não existia. Dos anos 80, é só o Conass. O Conasems é do final, é de 1989. O movimento municipal não veio para brincar, ele veio como uma realidade. Eu participei desses momentos e foi muito bacana ter a oportunidade de ver um processo desse e nele participar. Ao que tudo indica, o Conasems não vai acabar nunca mais. Esse é um processo que não volta atrás. Vários outros voltaram para trás, tanto pelas mãos dos reacionários como porque não eram oportunos ou por incompetência. Mas o Conasems 'colou'. Os prefeitos municipais, independentemente se eram clientelistas ou não, se eram do partido da situação ou da oposição, frente às demandas por liberdade democrática, apresentaram a seguinte postura ante o estado: “Quantas coisas no meu município o estado não está fazendo e eu sei fazer melhor? Eu comprovo que sei fazer melhor!" "Eu parto da posição puramente crítica das coisas erradas, ineficazes, dispersivas, clientelistas, que ferem a minha autonomia municipal e até minha dignidade municipal, a população que convive comigo, me denunciando todo dia dizendo: 'Nós faríamos melhor!'” Isso aconteceu na cultura municipal nos anos 80 ! Não foi só na saúde. O movimento municipal entra de uma maneira muito mais organizada antes da VIII Conferência de 1986.

\section{Revista}

O senhor já estava atuando na Secretaria $\mathrm{Mu}$ nicipal de Saúde de Campinas?

\section{Nelson Rodrigues dos Santos}

Eu vim para Campinas em 1978, convidado pe- 
lo secretário de saúde da época, Sebastião Morais, que é também um pioneiro na fase dos postinhos alugados. Fiquei coordenando os programas nos postos de saúde e, em 1983, o novo prefeito, eleito na leva do MDB antigo, da oposição à ditadura, Magalhães Teixeira, muito progressista e inovador, me chamou para ser secretário de saúde. Eu tomei posse e fiz um convênio com o Ministério da Saúde e comecei a substituir os postinhos alugados por postinhos construídos. Para decidir onde estes seriam construídos, chamei as sociedades de bairro, levei o mapa aereofotogramétrico da cidade nos bairros já sinalizando onde havia terrenos municipais - para não precisar comprar terreno. $\mathrm{O}$ secretário municipal de saúde 'deitou e rolou', porque tinha tanto por fazer, não precisava ser nenhum gênio para fazer coisa boa. A saúde periférica nos municípios feita pelos estados e pela União era terrível. Isso não aconteceu só em Campinas. Ribeirão Preto, Araçatuba, cidades médias de São Paulo, São José dos Campos, Santos e por aí afora. Eu liguei para os secretários municipais e começamos a nos organizar. Pegamos 17 cidades médias do estado de São Paulo e criamos um colegiado de secretários municipais de saúde. Esse colegiado começou a se reunir freqüentemente, e elaboramos um projeto de municipalização. Todas as cidades médias, com seus deputados, prefeitos e a população foram pressionar o governo Montoro para municipalizar. Flávio Goulart, secretário duas vezes em Uberlândia, tem um livro chamado Veredas [Municipalização: Veredas - Caminhos do movimento municipalista de saúde no Brasil. 1. ed. Brasília-Rio de Janeiro: ConasemsAbrasco, v. 1.67 p., 1996.], que resgata muito do movimento de municipalização.

\section{Revista}

E o Conass? Na medida em que os prefeitos estavam pressionando os governadores, os estados e governadores passaram a pressionar a União?

\section{Nelson Rodrigues dos Santos}

O Conass é anterior, nasceu em 1979 com Adib Jatene, que foi secretário de saúde do estado de São Paulo do governo Paulo Maluf. Ele tinha autonomia de gestão, era do Incor, da Fundação Zerbini. Jatene e os secretários estaduais de saúde da época fundaram o Conass. No final dos anos 70, a tensão que a ditadura deixou na so- ciedade brasileira estava crescente em toda a área social: assistência social, previdência social, saúde, habitação. Nos estados, os secretários, que tradicionalmente eram figuras de autoridade governamentais, tinham que dar conta do que acontecia nos municípios e nas periferias urbanas, pois nada era municipalizado - nem previdência, nem saúde, nem assistência, nem educação. O Conass surgiu como uma resposta dos secretários estaduais, pressionando o governo federal por mais recursos e mais delegação para os estados. As Ações Integradas tiveram um grande vetor dos estados. Toda capital de estado tinha dois prédios: o da Secretaria Estadual de Saúde e o da Superintendência Regional do Inamps. O prédio da Secretaria Estadual geralmente era um décimo do outro, a própria construção física, os móveis, os tapetes, da Superintendência davam de dez a zero. Isso correspondia mais ou menos aos orçamentos. Na época, o orçamento do Inamps era dez vezes maior que o orçamento do Ministério da Saúde. Tudo era dez vezes mais. Então os secretários estaduais, para dar resposta e ter estabilidade, pressionaram o governo federal para a Superintendência do Inamps fazer algum tipo de acordo. Se o Conass nasceu do fortalecimento do poder estadual para dar conta da tensão social nos estados no caso específico da saúde, o Conasems não nasceu só como uma resposta a uma tensão. O Conasems, quando era só o movimento municipal de saúde, nasceu no bojo do movimento da reforma sanitária, com um projeto de sociedade crescendo dentro dele. Estava dentro desse projeto resolver as tensões nas periferias urbanas, assumir os postinhos alugados e os postinhos construídos, mas a própria sucessão de etapas no movimento municipal mostra que é uma caminhada de movimento social, vem de baixo para cima. Os encontros municipais de saúde que ocorreram em João Pessoa, em Campinas, em Niterói e todos os outros eram encontros de construção, inovação, não parecia encontro institucional. E quando se formou o colegiado em São Paulo, eu fiquei sabendo que o Flávio Goulart liderou os secretários municipais das cidades médias de Minas Gerais e fez um colegiado! Pipocou em dois estados vizinhos dois colegiados! Quando nos conhecemos, começamos a ligar para os secretários dos outros estados fazerem colegiados também. O Conasems começou com colegiados 
de secretários municipais, e esses colegiados produziam documento atrás de documento, documentos técnicos para politizar os secretários municipais, para passar informação administrativa, de financiamento, administração, gestão e gerência de redes de saúde, contabilidade, prestação de contas. Nós começamos a ter força. Quando chegou a VIII Conferência - os próprios organizadores que eram companheiros nossos da reforma sanitária, companheiros do Cebes -, deram 12 vagas para os secretários municipais de saúde, porque era aparentemente desconhecido que existia não só responsáveis pela saúde dos municípios, mas que várias cidades estavam criando secretarias municipais de saúde e já estavam se organizando em colegiados estaduais. Quando nós soubemos das 12 vagas, começamos a telefonar - naquela época só tinha telefone, não tinha e-mail; para viajar, era um desespero, fazíamos uma viagem ou outra - mas começamos a rapidamente fazer uma pressão muito grande, e fizemos pressão indireta também através dos prefeitos, deputados e conseguimos que a comissão organizadora da VIII Conferência passasse de 12 para 82 vagas. E os 82 foram! Cada colegiado foi integralmente e completava a distribuição. Mas chegamos na VIII Conferência e a questão municipal não estava em nenhuma das pautas, não estava no programa. Então nós nos dividimos: numa parte do tempo, íamos para o plenário, para os grupos de trabalho, para cumprir a pauta da VIII Conferência; em outra, adotamos uma escada muito grande, de degraus muito largos, e ali virou uma espécie de anfiteatro. Ali fizemos muitas assembléias para discutir as nossas posições na pauta da VIII Conferência, eu era o portavoz, e no fim nós fizemos um relatório, uma proposta nossa, e pressionamos o Guilherme Rodrigues, relator da Conferência, para anexar no relatório final as nossas duas páginas. Um dos tópicos era a necessidade imperiosa de se criar uma organização nacional de secretários municipais. Mas não nasceu a sigla Conasems aí, não. Tinha um colegiado estadual, estávamos pensando num colegiado nacional. Após a VIII Conferência, o movimento municipal de saúde ampliou-se e começaram a surgir as associações de secretários municipais de saúde em cada Estado, que foram se transformando nos Cosems e, finalmente, em 1989, em um encontro nacional, é criado o Conasems.

\section{Revista}

Houve discussão sobre a formação de recursos humanos na área da saúde na VIII Conferência? Quem estava lá discutindo isso? Quem estava levando à frente? Os senhores, nesse movimento, estavam colocando essa questão também? Havia tensão?

\section{Nelson Rodrigues dos Santos}

A questão dos recursos humanos praticamente não foi discutida no simpósio de 1979. No simpósio de 1982, que apontava para a configuração de um sistema, já começou a se falar em recursos humanos, e o tema se torna mais relevante na preparação da VIII Conferência. 1983, 1984 e 1985 são anos de muitas reuniões, muitas discussões. Foram num crescendo e se falou mais de recursos humanos na VIII Conferência. O Plano de Cargos, Carreiras e Salários foi uma bandeira levantada no II Simpósio com muita categoria, com muito realismo, sem muito teoricismo, sem muita teoria da educação. A proposta de sistema de saúde que se desenhava nesse Simpósio, em 1982 - que já tinha feito as AIS, a integração entre Inamps, secretarias estaduais e Ministério da Saúde -, já estava mais visível, já era um decreto presidencial, e o preâmbulo para a configuração de um sistema já estava ali. Recomendações que antes eram mais teóricas, que vinham do PPREPS e de consultores internacionais, começaram a ganhar feitios de verdade, já estavam ficando perto: recursos humanos para aquele novo sistema de direitos universais e de atenção integral. A questão da integralidade era uma bandeira muito maior do que é hoje, porque a separação institucional era de tal ordem que a integralidade era muito cara e muito cativante. A questão da atenção integral à saúde, de que para exercer essa atenção era necessário um novo perfil. Isso se tornou uma outra bandeira: 'novo perfil' do profissional da saúde para esse novo sistema de atenção integral. Sua remuneração, sua capacitação, seu compromisso com a população eram decorrências de uma guinada em perfil de recursos humanos, e esses recursos humanos precisariam ser novos para um novo sistema. Esse novo sistema, além da integralidade, teria que exigir um compromisso do profissional, que não era 'alugado' para prestar um serviço, mas comprometido. Esses valores foram sendo bem sedimentados nesse Simpósio e na preparação 
depois para a VIII Conferência. A definição de 'clientela' foi cunhada no início dos anos de 80. Inclusive se ouvia isso da boca do Eleutério Rodriguez Neto. Ele teve papel fundamental nesse processo, foi líder disso. O tema recursos humanos tornou-se uma das bandeiras inabdicáveis da reforma sanitária. Não era só juntar o sistema integrado, compor um sistema nacional de saúde, juntar Inamps com Ministério da Saúde, nem era só sair do mercantilismo para uma política pública gratuita e de direitos. Era tudo isso, mas era também no microcosmo, na micropolítica de saúde, na ponta, equipes com um novo perfil profissional - com o generalista aparecendo, com peso, dentro do contexto. $\mathrm{Na}$ área pública, remuneração e carreira. Isso marcou o II Simpósio em 1982 e marcou muito mais a VIII Conferência. E foi fundamental isso para o que depois veio a ser a Comissão Nacional de Reforma Sanitária.

\section{Revista}

Eleutério Rodriguez Neto registra em sua tese que a proposta que saiu da Comissão Nacional de Reforma Sanitária foi polêmica porque o setor privado a considerou muito radical, enquanto parte do movimento sindical a considerou pouco ousada.

\section{Nelson Rodrigues dos Santos}

A experiência acumulada foi ajudando uma visão mais realista do processo. Por isso, eu acho que esse resgate é importante, para que pelo menos a memória ajude os protagonistas daqui para frente a militarem de uma maneira mais realista e mais produtiva - serem ou menos paranóicos, achar que está tudo pronto, ou menos derrotistas, achar que está tudo derrotado. O setor privado, na época representado pela Federação Brasileira dos Hospitais e pela Confederação das Misericórdias do Brasil - o lucrativo e o filantrópico, estava vendo o povão vindo, 4 mil pessoas em Brasília, o Arouca comandando, já tinha os seus motivos próprios para não cooperar. Mas tinha uma vertente que era inclusive majoritária no início da VIII Conferência, que não queria papo com o setor privado. Quem trouxe isso para a VIII Conferência foi a CUT. E trouxe a proposta da estatização total do sistema público de saúde, a ponto de o pessoal um pouco mais moderado, ou mais realista
- eu estava entre eles, o Arouca também - fazer um esforço muito grande no desenrolar da VIII Conferência para a discussão ficar: 'estatiza já' ou 'estatiza no processo'. E pudemos ganhar 'estatizar no processo'. São os dois lados!

\section{Revista}

Quando se discutiu na VIII Conferência, e durante todo esse processo da reforma sanitária, complementaridade do privado em relação ao público, e até o próprio processo de estatização progressiva e não de estatização já, partiu-se de uma análise de que o Estado não podia abrir mão imediatamente, ou romper naquele momento com o privado, porque a maioria dos leitos estava na mão daquele setor. Ao fazer um rompimento, ou uma estatização já, a população ia ficar desassistida, na prática, instalando um caos no setor saúde. A opção pela estatização progressiva se colocou também com uma perspectiva de, aos poucos, o público ir incorporando o privado.

\section{Nelson Rodrigues dos Santos}

É exatamente isso. Se a perspectiva for estatizar progressivamente, enquanto não estatizar tudo, enquanto houver necessidade de contratar ou conveniar o setor privado, pela Constituição, o setor privado tem que oferecer serviços como se público fosse. A FBH (Federação Brasileira de Hospitais) e a Confederação Nacional da Saúde, que representa o setor privado lucrativo, estão ao mesmo tempo no mercado e no SUS - a maior parte dos leitos é contratada pelo SUS. Pela jurisprudência constitucional, todos os serviços contratados pelo poder público funcionam como se público fossem. Então essa é uma relação não só contratual, mas de compromisso público, porque o contratante é o Estado, é o poder público, e, ao contratar, contrata uma oferta de serviços planejada pelo Estado. Quando o Estado contrata um hospital, contrata internações em cardiologia, gastroentereologia, ginecoobstetrícia, contrata ambulatório, laboratórios para exames, mas quer um certo número de cirurgias, um certo número de exames laboratoriais, um certo número de consultas. O planejamento da oferta é do Estado. Ele não tem hos-pitais ou estabelecimentos para executar toda a sua oferta, então complementa. Por isso essa jurisprudência está formada. Tudo que é 
contratado com recursos públicos é para funcionar como se público fosse, isto é, cumprir metas elaboradas pelo Estado, pelo contratante. O contratante é que define o que está contratando, define as metas de produção. A grande discussão nem é mais essa agora, se continua o compromisso de estatizar progressivamente, se vai ficar tudo estatal. Essa negociação feita pela VIII Conferência nunca voltou à tona nas conferências posteriores. Isso significa, implicitamente, que o desafio colocado para o desenvolvimento do SUS nesses anos todos é que quanto mais órgãos governamentais houver, melhor, mas que a meta, o objetivo de dar totalidade aos sistemas governamentais não é fundamental para que o SUS seja plenamente realizado. Se o setor privado contratado e conveniado complementar cumprir fielmente a oferta de serviços como se fosse público, pode ser negociada uma convivência. Essa é exatamente a diferença entre convênio e contrato: o convênio é juridicamente para os hospitais sem fins lucrativos, ou filantrópicos, que estariam teoricamente muito mais próximos de uma finalidade pública, não mercantilizada, e aí sim, segundo a Constituição e a lei, tem preferência aos lucrativos. Nas últimas décadas vem crescendo no mundo inteiro, e no Brasil começa nos últimos anos, uma tarefa de Estado que antes era irrisória, imperceptível praticamente, e hoje é importante, que é a tarefa regulatória. A regulação é uma série de mecanismos para acompanhar e assegurar o cumprimento da finalidade pública - não é contratar e deixar fazer o que quer, mas contratar com um mecanismo de acompanhamento regulador, para que os contratados e conveniados do SUS cumpram a tarefa como se públicos fossem. E a regulação também vai mais adiante, é a regulação do mercado na saúde. A Agência Nacional de Saúde não é SUS - essa é uma discussão muito grande, porque todos nós queremos que ela seja SUS, que tenha uma ligação e uma subordinação ao SUS - mas ela nasce como uma agência reguladora de mercado autônoma em relação ao SUS. Essa construção da tarefa regulatória, aplicada no SUS, seria criar mecanismos de regulação da oferta e utilização de serviços pelos hospitais e laboratórios privados conveniados e contratados no bojo de uma tarefa regulatória maior a partir de todas as unidades e serviços públicos governamentais. Para este desafio temos ainda muito caminho pela frente. Nos anos 90, os ideólogos do neoliberalismo colocaram para o setor público um sucateamento dos recursos humanos. Os anos 90 passaram a conhecer uma guinada no sentido contrário a tudo o que foi postulado e aprovado na VIII Conferência, na Conferência Nacional de Recursos Humanos, e depois até na gestão, nas tripartites e nas bipartites, nos anos 90. Esta guinada se deu em duas vertentes: econômica e nas tarefas do Estado. Na vertente econômica, o SUS teve uma puxada de tapete através do financiamento. O financiamento aprovado na Constituição nas disposições transitórias era no mínimo $30 \%$ do orçamento da Seguridade Social. E o financiamento federal decresceu ao invés de crescer! Caiu, em dados oficiais, de 1995 a 2004, de 85 dólares per capita para 62 dólares per capita. E conforme a descentralização vai acontecendo, os estados e municípios vão crescendo. De 2000 a 2004 - a partir de 2000 tem o Ciops, que mede a contabilidade dos orçamentos públicos da saúdeo per capita em dólares dos estados e municípios somados cresce de trinta e pouco para 64 dólares. O Ministério da Saúde decresce e a soma dos estados e municípios cresce e empata! Isso mostra um paradigma que vem dos anos 90, do neoliberalismo, que o poder federal reconcentra a arrecadação, mas desconcentra o gasto. Os estados e os municípios têm que pôr dinheiro a mais para conter as pressões sociais. E, além disso, o Estado mínimo: o Ministério da Saúde tem $75 \%$ de terceirizados e $25 \%$ de servidores federais. O que o Estado mínimo fez com o Ministério da Saúde? Levou às últimas conseqüências a estratégia do Estado mínimo é mínimo mesmo, reduziu no Ministério sua cultura e missão institucional. O Ministério da Saúde, que, apesar de todos os seus desvios preventivistas e campanhistas históricos, tinha concurso público e servidores que acumularam uma competência, uma respeitabilidade técnica importante. Isso foi sucateado. Acabou! Os anos 90 foram, gradativamente, colocando a terceirização e impondo e induzindo os estados e municípios a copiarem esse modelo. Uma grande parte das secretarias estaduais já está nesse processo, também terceirizando. $\mathrm{Na}$ escala de valores de políticas públicas, a idéia e o valor do serviço público foram substituídos pela idéia e o valor da privatização, da competição, do mercado e da terceirização. 


\section{Revista}

Como o Conselho Nacional de Saúde (CNS) se comporta, como é a sua composição? Por que ele tem uma comissão de recursos humanos, que inclusive vai organizar todo o debate em torno da NOB-RH (Norma Operacional Básica de Recursos Humanos do Sistema Único de Assistência Social - NOB-RH/Suas), e não tem uma comissão de formação em saúde, considerando que, no próprio artigo 200, uma das competências do SUS é ordenar a formação de recursos humanos?

\section{Nelson Rodrigues dos Santos}

Eu me lembro muito bem que no Simpósio de 1982, na VIII Conferência e na Conferência Nacional de Recursos Humanos se apontava claramente que a distribuição territorial dos profissionais tinha que ser de acordo com as necessidades da população, que dentro dessa distribuição territorial dos profissionais estivesse embutida a renovação dos perfis multiprofissionais. Entre essas mudanças de perfil está a emergência do generalista médico, na enfermagem, na odontologia, generalista esse que não era um simplificador da atenção à saúde, que teria a maior densidade tecnológica dos perfis profissionais. $\mathrm{O}$ generalista bem-informado e atualizado periodicamente. Essa visão do generalista estava colocada no Simpósio de 1982, na VIII Conferência e na Conferência Nacional de Recursos Humanos. O que precisa ser medido e avaliado é o tamanho da inflexão que houve a partir dos anos 90! Dezoito anos se passaram. Em 1994, 1995, quando o Ministério da Saúde criou, sob recomendação do Banco Mundial, o PSF e o Pacs parecia que estava 'inventando a roda'. Nossa discussão de Atenção Primária, de rede básica, de adscrição de clientela e de cobertura universal está discutida e 'consensada' direitinho já no começo dos anos 80 ! O que aconteceu? Deu um 'branco'? Deu um esquecimento e agora reinventa num outro modelo, compensatório, focalizante? Nossa escala de valores foi criada e assumida para a estruturação de um novo sistema, de uma nova política, não foi criado como compensatório! Felizmente este compensatório na prática não é total por causa de uma reação dos municípios. A maior parte dos municípios reagiu a ser só correia de transmissão de compensatórios e está tentando fazer do Pacs-PSF um elemento estruturante de todo o modelo de atenção. Reagem contra a estratégia de descolar o PacsPSF da rede de unidades básicas do SUS. Nos anos 80, com todos os embates passando pela Assembléia Nacional Constituinte, a adscrição de clientela, o acolhimento ao perfil generalista, a alta resolutividade da atenção básica, era um compromisso assumido para ser viabilizado pela totalidade das equipes dentro da rede de unidades básicas de saúde. O trabalho dentro da unidade básica foi pensado dentro do compromisso com o número de famílias. A amarração foi a rede de unidades básicas passar a ser a própria atenção básica resolutiva e paralelamente ao esfacelamento da rede, 'descolar' um Pacs-PSF para manter uma cobertura, manter uma inclusão que efetivamente mantém, mas sem eqüidade e sem integralidade. A força econômica puxando o tapete do financiamento agiu coerentemente: "Temos dinheiro para universalização e para a municipalização. Para o resto não temos". O chavão da inclusão era muito atraente, incluiu mesmo, só que para os serviços de baixíssimo custo dentro dos orçamentos que foram dados. Para $75 \%$ da população, que não é consumidora de planos privados de saúde, é o SUS pobre para os pobres, com 140 dólares por habitante/ano. Os $25 \%$ da população, que é o mercado de consumo que pode comprar plano privado, vão usar o SUS para complementar aqueles serviços e medicamentos de maior custo não cobertos pelo plano privado.

\section{Revista}

Pode-se dizer que o SUS existe?

\section{Nelson Rodrigues dos Santos}

Existe. Nós temos o SUS da Constituição, temos o SUS pós-constitucional e temos o SUS real, que é uma mistura dos dois. O SUS constitucional é o resultado da mobilização da população, consciente dos seus direitos, querendo uma política pública de direitos de cidadania com tudo que decorre daí: o Ministério Público, o Conasems, os Cosems, com os conselhos de saúde, com a militância da reforma sanitária. O SUS pós-constitucional é o SUS ditado economicamente pelo FMI e socialmente pelo Banco Mundial - tem dinheiro só para políticas focais e compensatórias; o SUS pobre para pobre. 
Os dois SUS convivem e conflitam permanentemente. Neste momento, o SUS pós-constitucional é hegemônico, e o SUS constitucional é contra-hegemônico. Mas um contra-hegemônico que não está fadado ao desaparecimento, porque os atores cresceram muito.

\section{Revista}

O senhor destaca a importância da ligação estreita entre a sociedade organizada e o Legislativo para as conquistas sociais na área saúde nos anos 80 . Nos anos 90, sua atuação no Conselho Nacional de Saúde possibilitou acompanhar de perto os movimentos sociais na saúde e as tensões políticas na área.

\section{Nelson Rodrigues dos Santos}

Olhando para os últimos 18 anos, já temos um bloco de coisas que aconteceram apontando numa direção inequívoca: a chegada da vertente neoliberal de um lado e da vertente social do mesmo neoliberalismo de outro lado pelo Banco Mundial, a puxada de tapete nos orçamentos públicos, que tem até um outro rótulo: a 'financeirização' dos orçamentos públicos - na qual os orçamentos passam a garantir as dívidas públicas crescentes, com os juros altos, e para isso se faz um superávit primário para afiançar esse pagamento, e agora a dívida vai muito além, o superávit primário paga uma parte dos juros da dívida, a outra parte é refinanciada ou acrescentada pela 'espremeção' do orçamento público. Esse é um projeto inteligente que atua nos valores da sociedade e em cada segmento da sociedade, incluindo, evidentemente, os segmentos que acompanham os conselhos de saúde. Como esse projeto invade o ideário dos usuários? Como ele invade o ideário dos profissionais? Como invade o ideário dos prestadores e dos governantes? De diferentes formas, com diferentes intensidades. Nós vimos que os usuários que, nos anos 80, tinham entidades que brigaram por uma Assembléia Nacional Constituinte, brigaram pelas liberdades democráticas, contra a ditadura, pelas diretas já em 1983, 1984, foram para a Assembléia Nacional Constituinte para desenhar uma nova sociedade e um novo Estado fora da ditadura, Estado este com políticas públicas de cidadania. Essas mesmas entidades, ano a ano, foram transmutando o seu ideário para o ideário do mercado e do corporativismo. Quem é a maior pleiteadora dos planos privados para a saúde a seus filiados senão a CUT? CUT que sentou conosco na Comissão Nacional da Reforma Sanitária! Que defendia a cidadania e um sistema de saúde gratuito, igualando o cidadão qualquer que fosse a sua classe social, a sua raça, se tivesse carteira assinada ou não. Não só a CUT, a Força Sindical também, igualzinho, as duas se igualaram nisso: é o sindicalismo de resultados e agora de negócios. Este é o pleito! Esses 18 anos foram um banho de valores individuais e de corporações. É a selva, é o nicho de mercado. Na sociedade e nos conselhos, os segmentos tendem a se comportar assim: "vou salvar o meu! Se der para ajudar a salvar o dos outros, eu até ajudo, senão atrapalhar a salvar o meu!" Isso está mexendo até numa parte de representações de trabalhadores de saúde e usuários nos conselhos. Aí vem um outro lado também: quando a sociedade se mobilizou, conquistou toda essa beleza de política pública, passou pela VIII Conferência, passou pela Constituição, passou pelo Simpósio de 1989 para conseguir a aprovação da lei orgânica da saúde, não havia conselhos de saúde. Isso tem que fazer cair a ficha da gente para coisas muito simples voltadas um pouquinho mais para o 'grande': a sociedade, consciente dos seus direitos, mobilizada e organizada, vai em cima do Estado e puxa o Estado para ela. E o lado que ela mais pega é o Legislativo, é onde sensibiliza mais. O Executivo é onde estão concentrados os interesses anti-sociais - é a caixa do cofre, o Ministério da Fazenda etc. Talvez se não houvesse a vinda do neoliberalismo no Brasil, os conselhos de saúde estivessem hoje muito diferentes. Continuariam nesse mesmo empuxo que a sociedade organizada fez nos anos 80. Tanto que a sociedade organizada nessa época, quando conquistou a lei orgânica da saúde, qual foi a conquista para os conselhos? Que eles atuem, em primeiro lugar, na formulação de estratégias e, em segundo lugar, no controle da execução das políticas. No controle da execução das políticas eles foram crescendo e atuam bastante, são fiscais. O perfil, a cultura da fiscalização foi assumida, foi desenvolvida. Eles acompanham os orçamentos, decompõem a execução orçamentária dos projetos etc. E quanto à formulação de estratégias? O Conselho Nacional de Saúde tem possibilidade de atuar na formulação de estratégias federais? Ele pôde discutir se era para implementar só a universa- 
lidade e a municipalização ou implementar o conjunto todo de princípios e diretrizes da lei, a igualdade, a integralidade e a regionalização? Por que a regionalização não se deu?

\section{Revista}

Não discutiu. Mas, em alguns outros momentos, o Conselho teve um papel relevante. Lembramos, por exemplo, quando o ministro Bresser Pereira, no primeiro governo FHC, começou a implantar a reforma do Estado.

\section{Nelson Rodrigues dos Santos}

As 12 primeiras Organizações Sociais (OS) do Bresser eram 12 hospitais na gestão federal. Eu era coordenador da secretaria executiva do CNS e era minha função redigir os documentos do Conselho e agendar as discussões com os técnicos do Bresser e comissões da Câmara dos deputados federais. Aí sim, você vê a importância do Poder Legislativo: novamente, foram a sociedade e o Poder Legislativo que puderam ter força para segurar isso. Foram impedidas as OS para o SUS dentro do Poder Legislativo, dentro da Câmara. O Conselho se mobilizou, fizemos dois grupos de trabalho, foram dois relatórios. O primeiro quem coordenou foi o Gilson Cantarino, que era conselheiro na época - ainda era secretário municipal de saúde, e o segundo foi o Sérgio Piola, do Ipea (Instituto de Pesquisa Econômica Aplicada) - que era conselheiro também. Foram dois relatórios retumbantes, para não deixar pedra sobre pedra na proposta do Bresser. Rapidamente reproduzi esses relatórios e distribuí na mão de todos os deputados da Comissão de Seguridade Social e Família e da Comissão de Assuntos Sociais do Senado, propusemos uma audiência pública que ocorreu e o Bresser perdeu ali. Foi um momento que infelizmente não chegou a ser a regra. Quando certos problemas conseguem unir, problemas nocivos como foi essa proposta, que estava dentro da tese do Estado mínimo, o Conselho rapidamente conseguiu mobilizar as entidades, que rapidamente foram para o Legislativo e impediram a ação do Executivo. Um outro exemplo de uma grande jogada do Conselho Nacional de Saúde: sob uma consultoria do Banco Mundial, uma missão desse banco foi a Brasília e diagnosticou que o SUS estava criando muita tensão com filas para a atenção básica reprimida nas capitais e grandes centros ur- banos no Brasil, e recomendou que uma boa maneira de ajudar a esvaziar essas filas era abrir um plano privado de baixíssimo custo para a classe média baixa urbana. Mesmo que os compradores tivessem que retornar ao SUS para um atendimento de maior custo, as filas nas unidades básicas diminuiriam. E o MS encomendou à Agência Nacional de Saúde que fizesse uma proposta desse plano barato. Criou uma briga com as operadoras, porque teria que criar novas operadoras para operar isso, ou as operadoras privadas fariam esses planos baratos. Houve uma medida provisória, assinada pelo presidente da República, que foi para o Conselho que se mobilizou novamente, impedindo-a. Mas o conselheiro não é a sociedade. Tem os usuários, os profissionais e os prestadores. Mas os representantes não são os diretores e líderes das entidades, sejam dos usuários, dos profissionais ou dos prestadores. A liderança, o presidente, o vice-presidente, o diretor-executivo das entidades via de regra não são conselheiros. Houve uma baita desmobilização por causa disso. Os conselheiros representam as entidades dentro do Conselho, mas não as representam no conjunto da sociedade. O que ele tem que fazer? Tem que ter um hiperativismo na diretoria da sua entidade, tem que freqüentar as assembléias e as reuniões de diretoria da sua entidade. O que não acontece. Os poucos momentos em que o Conselho Nacional de Saúde pôde mobilizar alguma coisa foi nos pontos muito incontornáveis, muito agressivos contra a sociedade, e que pudemos mobilizar as diretorias das entidades. Se os conselhos de saúde tivessem seguido o mesmo ritmo com que a sociedade vinha participando nos anos 80 , jamais eles permitiriam, a começar do Conselho Nacional, mas também os estaduais e municipais, só implementar a universalidade e a municipalização e deixar na gaveta a integralidade, a igualdade e a regionalização.

\section{Revista}

Há, no interior do Conselho Nacional de Saúde, alguma discussão sobre formação profissional? Que novo modelo de escola poderia haver para contemplar uma nova ética social para os serviços públicos de saúde?

\section{Nelson Rodrigues dos Santos}

Há aí realmente um nó muito constrangedor 
que não está desatado na nossa realidade. A Comissão Interinstitucional de Recursos Humanos do Conselho Nacional de Saúde foi formada com um nome genérico, 'recursos humanos', e ali estão embutidos formação, utilização, currículos, mas ela nunca se desenvolveu minimamente no que está estabelecido na Constituição e na lei. Daí decorrem várias conclusões: uma delas é o chamado aparelho utilizador, o mercado que utiliza, privado e público, que absorve profissionais, na medida em que no SUS nós temos predominando a dupla militância - metade no privado, metade no público, e o público paga pessimamente. Isso predomina na atenção básica e na média complexidade. Na alta complexidade menos, porque eles remuneram melhor. No SUS, na atenção básica e na média complexidade, predomina a cultura da sobrevivência dos profissionais da saúde. Em nome da sobrevivência eles vão complementar no privado. Mas no privado, também, com o mercado disputado como está, eles precisam de mais inserções para somar uma coisa que possa ser chamada de complementação, porque uma só não dá para complementar também. Isso induz o próprio perfil do profissional. Pega o médico, a enfermeira, o psicólogo, quem você quiser de nível superior, e pega os técnicos. Quando a gente fala da educação na área da saúde, ela foi duramente atingida durante a ditadura, e acho que mais duramente atingida ainda no neoliberalismo dos anos 90 , e coloca para o SUS um desafio muito difícil ordenar um mercado caótico no setor privado e mais caótico na ligação público-privada que absorve recursos humanos em saúde. Ordenar a formação de recursos humanos para o SUS implica não só formar logicamente mecanismos coerentes com as diretrizes do sistema de cidadania, isto é, multiprofissionalismo técnico e de nível superior, mas implica estar transformando o aparelho utilizador que vai receber esses profissionais. Na área médica isso é visível, há trabalhos mostrando que numa graduação, numa pós-graduação, numa residência, numa especialização, podem ser formados profissionais com perfis coerentes para atendimento à população, com acolhimento, com vínculo para a responsabilidade sanitária, para a resolutividade. Dali a cinco anos você encontra o exaluno e ele é outro: “Eu? Não fiz isso, não! Não existe essa pessoa! Estou aqui fazendo outra especialidade, estou sobrevivendo. Tenho família, tenho filho, trabalho em três planos privados cinco dias por semana, trabalho no SUS um dia por semana." Eu levava grupos de alunos de medicina a unidades básicas, para discutir com eles. Você faz isso e eles ficam solidários com a população e revoltados com os médicos que não comparecem à unidade básica, sem perceber que dali a quatro anos eles é que não vão comparecer à unidade básica, fatalmente. Isso no médico, valendo para os demais profissionais. Tem que haver essa compatibilização, essa transformação conjunta: melhor formação simultaneamente a melhor utilização e condições de trabalho.

\section{Nota}

1 Entrevista concedida a Júlio César França Lima e Ialê Falleiros Braga, professores-pesquisadores do Laboratório do Trabalho e da Educação Profissional em Saúde (Lateps) da Escola Politécnica de Saúde Joaquim Venâncio/Fiocruz. 
